\title{
Inhaltsverzeichnis
}

Hans-Peter Bayerdörfer

Umrisse und Probleme des Themas . . . . . . . . . . . . . 1

Elmar Buck

Außenseiter auf der Bühne - zu den Konditionen des

Theaters . . . . . . . . . . . . . . . . . . . . . . . 24

Gunnar Och

Lessings Lustspiel "Die Juden" im 18. Jahrhundert -

Rezeption und Reproduktion . . . . . . . . . . . . . 42

Arno Paul

Die Formierung des jüdischen Theaterpublikums in Berlin

im späten 18. Jahrhundert. Eine quellenkritische Skizze . . . . . . . . . 64

Hans-Joachim Neubauer / Michael Schmidt

Rollenspiele. Antijüdische Kontexte des frühen bürgerlichen

Lachtheaters . . . . . . . . . . . . . . . . . . . . . . . 85

Andreas Höfele

Judengestalten im englischen Theater (1700-1900) . . . . . . . . . . 115

\section{Elmar Goerden}

Der Andere. Fragmente einer Bühnengeschichte Shylocks

im deutschen und englischen Theater des 18. und 19. Jahrhunderts . . . . 129 
VIII

\section{Manfred Wegner}

Materialien zu Figur und Gestalt des Juden im Puppen-

theater des 19. Jahrhunderts . . . . . . . . . . . . . . . . . . . . . . . . . . . 164

\section{Hilde Haider-Pregler}

Ausgrenzungen. Auswirkungen antisemitischer Tendenzen

in der Kulturpolitik auf das österreichische

Theater von der Jahrhundertwende bis $1938 \ldots \ldots$. . . . . . . . . . . . . . 184

\section{Henning Rischbieter}

Theater als Kunst und als Geschäft. Über jüdische

Theaterregisseure und Theaterdirektoren in Berlin 1894-1933 . . . . . 205

\section{Malgorzata Leyko}

Das jüdische Theater in Lodz, Stadt dreier Nationen . . . . . . . . . . 218

Jens Malte Fischer

Die "jüdisch-negroide Epoche". Antisemitismus im

Musik- und Theaterleben der Weimarer Republik . . . . . . . . . . . 228

\section{Erika Fischer-Lichte}

Retheatralisierung des Theaters als Emanzipation: das

"Staatliche Jüdische Theater" in Moskau 1920-1928 . . . . . . . . . . . 244

\section{Freddie Rokem}

From Marginality to Centrality. Jew and non-Jew in the Hebrew Inter-War Theatre $(1917-1939) \ldots \ldots \ldots \ldots \ldots \ldots$

\section{Margarita Pazi}

Paul Kornfelds Drama Jud Süß, 1933, und die dramatische

Bearbeitung des Feuchtwangerschen Romans in hebräischer Sprache von Avi-Shaul, $1933 \ldots \ldots \ldots \ldots \ldots$. . . . . . . . . . . . 281 
Barbara Panse

Antisemitismus und Judenfiguren in der Dramatik des

Dritten Reiches . . . . . . . . . . . . . . . . . . . . . . . . 299

\section{Heidelore Riss}

Das Theater des Jüdischen Kulturbundes, Berlin.

Zum gegenwärtigen Forschungsstand . . . . . . . . . . . . . . 312

\section{Georg-Michael Schulz}

Kampfstïck und Bibelrevue. Die Auseinandersetzung mit

dem Antisemitismus im Drama jüdischer Autoren

während der 30er Jahre . . . . . . . . . . . . . . . . . . . 339 
